\title{
Statistical analysis of trends in sweet cherry flowering data across Europe
}

\author{
Bénédicte Wenden ${ }^{1,2}$, Mahendra Mariadassou ${ }^{3}$, José Antonio Campoy ${ }^{1,2}$, José Quero-Garcia ${ }^{1,2}$ \\ and Elisabeth Dirlewanger ${ }^{1,2}$ \\ ${ }^{1}$ INRA, UMR 1332 Biologie du Fruit et Pathologie, F-33140 Villenave d'Ornon, France \\ ${ }^{2}$ Univ. Bordeaux, UMR 1332 Biologie du Fruit et Pathologie, F-33140 Villenave d'Ornon, \\ France \\ ${ }^{3}$ INRA, UR1404 Unité MaIAGE, F-78350 Jouy-en-Josas
}

\begin{abstract}
In temperate fruit trees, most key phenological stages are highly dependent on environmental conditions. In particular, correct timing for dormancy and flowering is essential to ensure good fruit production and quality. As a result, in a swiftly-changing environment, temperate fruit crop adaptation in many areas will be at risk in the coming decades. Global changes in environmental conditions include warmer winters and higher risks of frosts in the early spring, which may lead to a wide range of problems in relation to flower and fruit set, sun-scald, cross-pollination or novel host-pest interactions.

With the final aim of better understanding the response of flowering to climatic conditions, we present a large-scale statistical analysis of flowering data for sweet cherry (Prunus avium) cv. 'Burlat' from three sites in Europe, characterized by contrasted climatic conditions. These phenological data were provided through the Ctifl, a national network of experimentation and the sweet cherry European COST Action that INRABordeaux is leading. This approach allowed extracting the main trends in flowering behaviour under different temperature conditions, and highlighted key periods with significant temperature effect.

These results lead to a finer approach for phenology modelling and represent the first step towards developing a predictive model for flowering in sweet cherry based on both genomic and phenology data.
\end{abstract}

Keywords: Prunus avium L., Partial Least Square Regression, phenology

\section{INTRODUCTION}

Climate change is now well documented (IPCC13) and its effects on plant phenology and more specifically on changes in the timing of phenophases in fruit trees have been observed for decades (Miller-Rushing et al., 2007). Current estimates of advancing phenology, including earlier flowering, are 1.9-5 days per ${ }^{\circ} \mathrm{C}$ (Menzel et al., 2006; Wolkovich et al., 2012). In other locations, however, spring phases have been observed to occur later (Atkinson et al., 2013; Elloumi et al., 2013), which might be the consequence of warmer autumn and winter temperatures affecting the chill requirements during dormancy.

Such alterations might threaten temperate fruit production and thus worldwide economy. As a consequence, a better understanding of temperature response and sensitivity of fruit trees phenology is essential to foresee the changes to come and to have the ability to overcome the effects of climate change on fruit tree productivity. Partial least squares (PLS) regression is a powerful statistical tool to detect distinct temperature phases as demonstrated on walnuts in California (Luedeling and Gassner, 2012), cherry trees in Germany (Luedeling et al., 2013) and chestnuts in China (Guo et al., 2013). In this study, we used the PLS approach to analyse the temperature sensitivity of sweet cherry in different European locations and compare the flowering response between different latitudes. Results provide key information to identify trends in temperature response and to develop more adjusted phenology models. 


\section{MATERIALS AND METHODS}

Data for sweet cherry cv. 'Burlat' flowering time were used in this study. They were collected from three different locations. 180 flowering dates were recorded for 'Burlat' at the experimental orchard of INRA Bordeaux research centre located in Toulenne near Bordeaux, France $\left(44.58^{\circ} \mathrm{N},-0.28^{\circ} \mathrm{E}\right)$ for 32 years of observation from 1981 to 2012 . For the CTIFL orchard located in Bellegarde, France $\left(43.76^{\circ} \mathrm{N}, 4.46^{\circ} \mathrm{E}\right), 139$ data points were collected from 1982 to 2012. 24 flowering dates were also collected at Klein-Altendorf, Germany, at the research station of the University of Bonn $\left(50.40^{\circ} \mathrm{N}, 6.99^{\circ} \mathrm{E}\right)$ between 1978 and 2008.

Short gaps in daily temperature data were closed by linear interpolation, as described in Luedeling et al. (2013). As proposed in Luedeling and Gassner (2012), an 11-day running mean of daily temperatures was constructed, which smoothes the temperature curve and eases the interpretation of PLS regression (PLSR) outputs (Figure 1).

We used the $\mathrm{R}$ package ChillR (Luedeling, 2013) which includes all procedures described in the different PLSR studies on fruit trees (Luedeling and Gassner, 2012; Guo et al., 2013; Luedeling et al., 2013). These functions were used to analyze the response of sweet cherry $\mathrm{cv}$. 'Burlat' flowering dates to variation in mean daily temperatures during the 365 days of the year, from June to July.

The major outputs of the PLS analysis are the variable importance in the projection (VIP) and standardized model coefficients. Periods with VIP scores higher than the threshold set to 0.8 as previously described (Luedeling and Gassner, 2012), and high absolute values of model coefficients represent the relevant phases when temperatures have a significant effect on flowering dates in 'Burlat'. Positive coefficients indicate that warm temperatures during the given period delay flowering, or that cold temperatures hasten flowering, whereas negative coefficients reveal that warmer temperatures lead to earlier flowering dates.

\section{RESULTS AND DISCUSSION}

Long time series for the sweet cherry cv. 'Burlat' in three contrasted European locations confirmed that flowering periods were significantly delayed in northern sites such as Bonn (Figure2), where flowering began between the $3^{\text {rd }}$ of April and the $3^{\text {rd }}$ of May, with an average around the $17^{\text {th }}$ of April, while beginning of flowering was recorded as early as the $11^{\text {th }}$ of March in both Bordeaux and Bellegarde, and average dates of flowering on the $29^{\text {th }}$ and $26^{\text {th }}$ of March respectively.

PLSR models explaining the dependence of flowering dates to mean daily temperatures were well fitted to the data with high $\mathrm{R}^{2}$ values (Figure 3; $\mathrm{R}^{2}$ are $82.72 \%, 75.85 \%$ and $95.96 \%$ for Bordeaux, Bellegarde and Bonn, respectively), which confirmed a high correlation between flowering time and temperature conditions.

PLSR coefficients give information on the strength and the cold/warm effect of temperatures on flowering time. However, only the periods characterized by a VIP threshold value greater than 0.8 , are considered to have a significant effect of the temperatures on flowering time. Although the coefficients varied greatly over the 365 days, two main distinct groups of significant coefficients were identified for the three locations (Figure 4).

\section{Endodormancy and cold responses}

The timing of flowering is directly dependent on a proper dormancy release and bud growth, which are controlled by environmental factors, mainly temperature in sweet cherry. Winter bud dormancy can be divided into two main stages: endodormancy followed by ecodormancy (Lang et al., 1987). During endodormancy, even under optimal climatic conditions, the plant will not grow and will need sufficient accumulation of cold temperatures, namely chilling requirements, to trigger dormancy release. Subsequently, ecodormancy starts when buds are able to grow but low temperatures inhibit bud break. Flowering occurs when 
temperatures increase and heat requirements for bud growth are satisfied. Consequently, for endodormancy, we expected to clearly identify chilling periods defined by positive coefficients with highly significant VIP in the PLSR results. However, there was no relevant pattern in autumn and winter temperatures for the three experimental sites (Figure 4). In Bonn, in particular, only a short peak at the beginning of November indicated a response to cold temperatures. This lack of significant cold effect validate the absence of limitation in terms of cold temperature, meaning that the low winter temperatures in Bonn (Figure 1) appear to be sufficient to fulfill 'Burlat' chill requirements every year. This observation is also true for Bordeaux and Bellegarde with no long period of significant cold response except for two distinct peaks with VIP values greater than 0.8 (Figure 4). Both peaks are in autumn but the limiting cold phase is at the end of September in Bordeaux while around mid-November in Bellegarde. These contrasts might be the consequence of the different climatic zones since Bordeaux is under the influence of an oceanic climate, with mild and wet autumns while Bellegarde is characterized by a dryer environment. Global environmental conditions might differently affect physiological processes involved in the dormancy onset in autumn.

\section{Ecodormancy and response to warm temperatures}

Around February and March, negative coefficients with high absolute values and VIP values exceeding 0.8 corresponded to a critical phase when warm temperatures were needed to hasten flowering in sweet cherry cv. 'Burlat' in the three locations. This is in agreement with the heat requirement period, related to the ecodormancy. Highly significant results confirm that climatic conditions mostly affect flowering time through temperatures at the end of winter. This is even further validated by the differences observed between experimental sites. The critical heat requirement period in Bonn, that lasts from mid-January to mid-May is longer than in Bordeaux and Bellegarde (Figure 4). Lower spring temperatures in Bonn (Figure 1) could explain these differences since buds might need a longer period to fulfill the heat requirement necessary to flower. These results are consistent with the forcing phase previously identified for the sweet cherry cv. 'Schneiders späte Knorpelkirsche' (Luedeling et al., 2013).

\section{Response to summer warm temperatures}

PLSR results for all three experimental sites reveal a significant peak with positive coefficients in July (Figure 4). Rather than a positive cold effect on flowering time, it is likely that during this period, warm if not hot temperatures negatively affect dormancy onset. Jonkers (1979) demonstrated a tendency for dormancy to deepen when the temperatures at which the apple and pear buds had been formed were too high. Similar results were found in black alder (Alnus glutinosa [L.] Moench; Heide, 2003) and Acer platanoides (Westergaard and Eriksen, 1997).

\section{CONCLUSION}

In the context of climate change and its effects on flowering phenology, it is essential to better understand the phenological response to temperature. PLS regressions have been used on phenological data in trees for several years and have proven their value to effectively delineate key periods with significant temperature effect. We applied these analyses to sweet cherry data on the control cultivar 'Burlat' from three experimental sites with contrasted climate conditions. For the three locations, the forcing period, characterized by a response to warm temperatures, was highly correlated to variations in flowering time, thus validating the key role of spring temperatures in the control of flowering time. Further comparisons of responses for genotypes with contrasted chill and heat requirements should provide useful information on the genetic determinism for heat requirements. Results were less clear for chill requirements as no marked pattern could be observed in the three locations. Similar analyses of flowering dates 
collected from areas with milder winter temperatures, such as the South of Spain, might reveal more limiting cold responses. Sweet cherry is a fruit tree species with a low turnover in terms of the main varieties and thus long time series for control varieties such as 'Burlat' are available from multiple locations. In particular, data obtained in the context of the sweet cherry European COST Action that INRA-Bordeaux is leading should allow collecting and analysing more flowering data from sites with contrasted climatic conditions. Knowledge acquired on the main flowering responses to temperature provide primordial information to develop more accurate phenological and mechanistic modelling tools.

\section{ACKNOWLEDGEMENTS}

The authors would like to thank the Ctifl for Bellegarde data, and Michael Blanke for providing data from the University of Bonn.

\section{Literature cited}

Atkinson, C.J., Brennan, R.M. and Jones H.G. 2013. Declining chilling and its impact on temperate perennial crops. Environ Exp Bot 91:48-62

Elloumi, O., Ghrab, M., Kessentini, H. and Ben Mimoun, M. 2013. Chilling accumulation effects on performance of pistachio trees cv. Mateur in dry and warm area climate. Sci Hortic (Amsterdam) 159: 80-87

Guo, L., Dai, J., Ranjitkar, S., Xu, J. and Luedeling, E. 2013. Response of chestnut phenology in China to climate variation and change. Agric For Meteorol 180: 164-172

Heide, O.M. 2003. High autumn temperature delays spring bud burst in boreal trees, counterbalancing the effect of climatic warming. Tree Physiol 23: 931-6

Jonkers, H. 1979. Bud dormancy of apple and pear in relation to the temperature during the growth period. Sci Hortic (Amsterdam) 10: 149-154

Lang, G., Early, J., Martin, G. and Darnell ,R. 1987. Endo-, para-, and ecodormancy: physiological terminology and classification for dormancy research. Hort Sci 22: 371-377

Luedeling E (2013) chillR: statistical methods for phenology analysis in temperate fruit trees. $\mathrm{R}$ package version 0.54 . http://cran.r-project. org/web/packages/chillR/

Luedeling, E. and Gassner, A. 2012. Partial Least Squares Regression for analyzing walnut phenology in California. Agric For Meteorol 158-159: 43-52

Luedeling, E., Kunz, A. and Blanke M.M. 2013. Identification of chilling and heat requirements of cherry trees-a statistical approach. Int J Biometeorol 57: 679-89

Menzel, A., Sparks, T.H., Estrella, N., Koch, E., Aasa, A., Ahas, R., Alm-Kübler, K., Bissolli, P., Braslavská, O., Briede, A., et al. 2006. European phenological response to climate change matches the warming pattern. Glob Chang Biol 12: 1969-1976

Miller-Rushing, A.J., Katsuki, T., Primack, R.B., Ishii, Y., Lee, S.D. and Higuchi, H. 2007. Impact of global warming on a group of related species and their hybrids: cherry tree (Rosaceae) flowering at Mt. Takao, Japan. Am J Bot 94: 1470-8

Westergaard, L. and Eriksen, E. 1997. Autumn temperature affects the induction of dormancy in first-year seedlings of Acer platanoides L. Scand J For Res 12: 11-16

Wolkovich, E.M., Cook, B.I., Allen, J.M., Crimmins, T.M., Betancourt, J.L., Travers, S.E., Pau, S., Regetz, J., Davies, T.J., Kraft, N.J.B., et al 2012. Warming experiments underpredict plant phenological responses to climate change. Nature 485: 494-497 


\section{Figures}
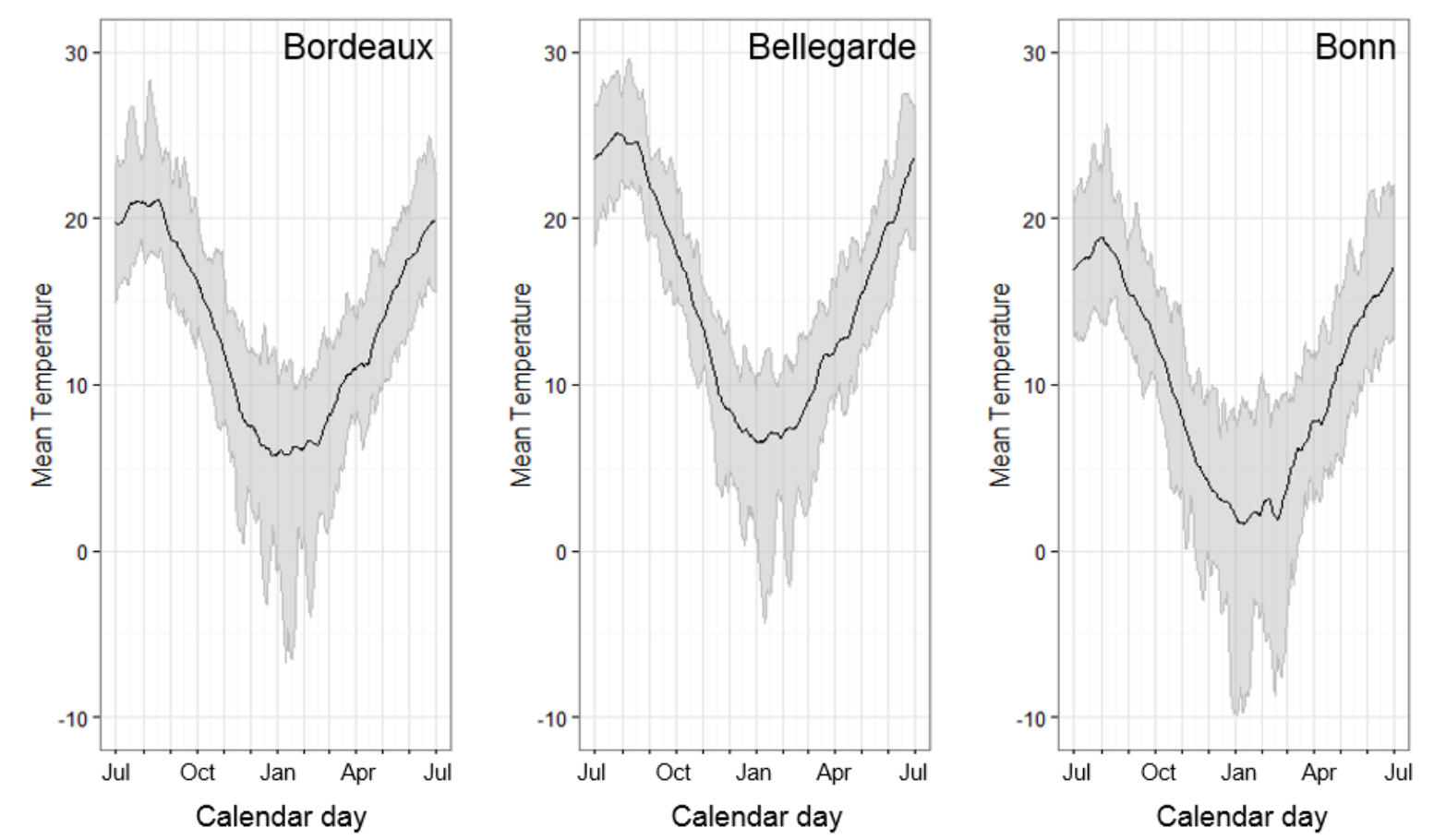

Figure 1. 11-days averaged temperatures used for analyses. Line is overall average of running mean over 11 days of all years temperatures, and ribbons correspond to running mean over 11 days for the whole period (1980 - 2012 for Bordeaux, 1981 - 2012 for Bellegarde and 1978 2008 for Bonn).

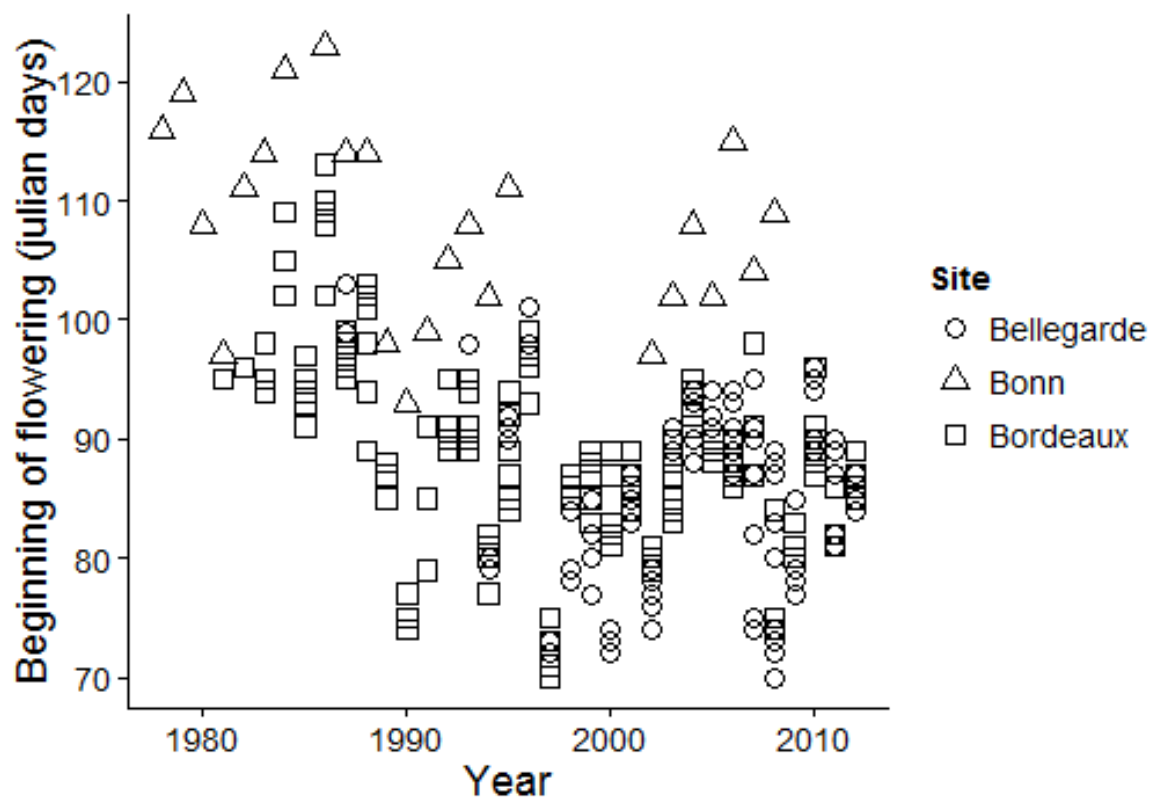

Figure 2. Flowering data used for the study from Bonn (Germany), Bordeaux (France) and Bellegarde (France). Dates are of beginning of flowering for the sweet cherry cv. 'Burlat'. 

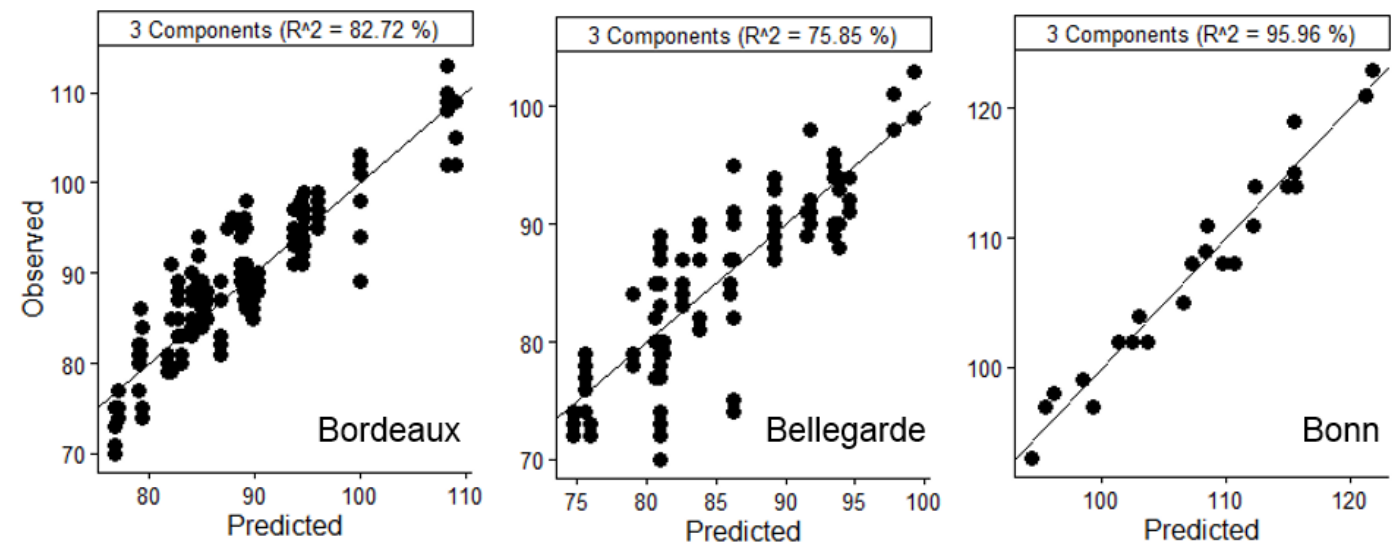

Figure 3. Data for beginning of flowering collected in Bordeaux, Bellegarde and Bonn compared to flowering values predicted by the PLS regression based on daily temperature data. Each point corresponds to an observed flowering date, compared to the predicted value using the PLS regression based on the temperature data for the year of observation. The black line is indicated as a comparison $(\mathrm{y}=\mathrm{x})$. To ease analysis between the three sites, all PLS regressions were calculated with 3 components, which define the dimensions of the regressions, and $\mathrm{R}^{2}$ is an indication of the regression's accuracy.
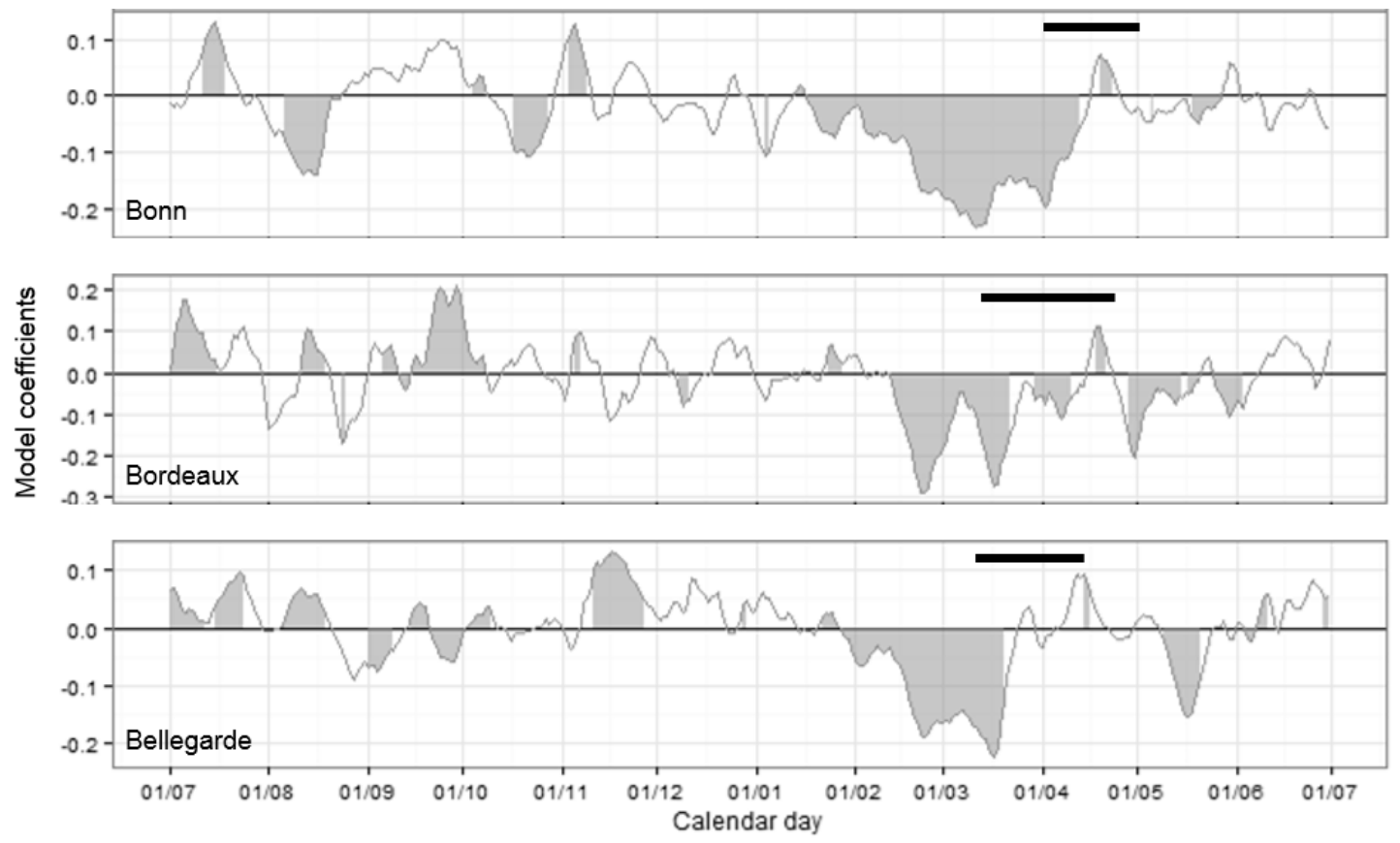

Figure 4. Results for the model coefficients of Partial Least Squares (PLS) regression for beginning of flowering dates in sweet cherry cv. 'Burlat', in correlation with mean daily temperature, averaged over 11 days, from July $1^{\text {st }}$ (Year N-1) to June $30^{\text {th }}$ (Year N). Grey areas indicate that the Variable Importance on Projection (VIP) is greater than 0.8 , corresponding to the threshold chosen for significant effect of the temperatures on flowering time. Positive coefficients indicate that warm temperatures during the given period delay flowering, or that cold temperatures hasten flowering, whereas negative coefficients reveal that warmer 
temperatures lead to earlier flowering dates. The thick black line indicates the range of flowering dates over the observation years. 